\title{
Japanese set to X-ray Sun
}

\section{Tokyo}

NEXT month, Japan will launch yet another X-ray observation satellite, this one designed to observe solar flare activity of the Sun. This series of satellites has allowed Japanese astrophysicists to capture a leading position in the field of X-ray astronomy.

The Solar-A satellite, due to be launched on 26 August, will be the world's only scientific satellite dedicated to observation of the Sun during the present period of maximum solar flare activity. It will carry both hard and soft X-ray telescopes, as well as a Bragg crystal highresolution $\mathrm{X}$-ray spectrometer and a wide-

WEAPONS TRADE

\section{Japan embarrassed by} weapons sale to Iran

\section{Tokyo}

IN an untimely embarrassment for the Japanese government, police last week raided a subsidiary of a major Japanese electronics company that is suspected of exporting high-technology military related equipment to Iran during the Iran-Iraq war.

Disclosure of the exports by Japan Aviation Electronics, a subsidiary of NEC, comes at a time when Prime Minister Toshiki Kaifu was planning to portray Japan at this month's summit of leading industrialized nations in London as a model country that does not engage in military-related trade.

The executive managing director of Japan Aviation Electronics admitted on 5 July that the company had repaired crucial components of the guidance system of US-made Sidewinder missiles for Iran during the Iran-Iraq war. Police also suspect that the company manufactured gyroscopes and other components of the inertial navigation systems for missiles and aircraft and exported them to Iran at a time when the United States and other Western countries had placed an arms embargo on the Middle East country.

The exports are a clear violation of Japan's strict ban on military exports. And government officials say that, if the charges are substantiated, the company could be prohibited from engaging in the export business for three years under regulations introduced following the Toshiba scandal of a few years ago. In 1987, a Toshiba subsidiary was found to have exported sophisticated milling machines that allowed the Soviet Union to make silent propellers for submarines.

Foreign Ministry officials argue that the government's harsh response to the affair indicates that Japan is serious about arms trade control.

D.S. band spectrometer for detecting soft Xrays, hard $\mathrm{X}$-rays and gamma rays.

The soft X-ray telescope, developed in collaboration with US scientists, will be able to detect and take automatic snapshots of the thermal activity of solar flares at intervals of a few seconds.

Meanwhile, the hard X-ray telescope will pick up the activity of high-energy electrons in flares with a time resolution of a second or better. Solar-A follows the institute's Hinotori satellite launched in 1981, which observed soiar flare activity during the last solar maximum and helped to establish Japan's foothold in this field.

In the intervening period of quiet solar activity, the Institute of Space and Astronautical Science has developed its expertise in X-ray satellite observations by launching the X-ray astronomy satellites Tenma (in 1983) and Ginga (in 1987). In 1993, the institute will launch a follow-up satellite to Ginga called ASTRO-D.

This series of satellites has nurtured the growth of Japanese $\mathrm{X}$-ray astronomy considerably. Indeed, more than 50 per cent of 160 authors contributing papers on $\mathrm{X}$-ray astronomy to the Astrophysical Journal in 1990 were either Japanese (25 per cent) or Western scientists who used Japan's Ginga satellite.

A key reason for Japan's success has been the ability of the space institute to launch low-cost satellites (a few tens of millions of dollars) every few years, and thereby maintain almost continuous observations and hold together and build teams of researchers. In contrast, satellites in Europe and the United States tend to cost hundreds of millions of dollars; the result is long gaps between satellite launches because of lack of funds, making it impossible to collect data continuously and very hard to keep research teams together.

The Japanese space institute can produce low-cost satellites because the institute's scientists and engineers themselves design and build the satellites, launch them, collect the data and publish the results. There is only minimal use of outside contractors.

This approach, however, does have its disadvantages. The US National Aeronautics and Space Administration (NASA) and the US Jet Propulsion Laboratory recently suggested that the Japanese space institute should use NASA ground stations in several places around the world so that Solar-A can maintain continuous observations. But the institute's Yoshiaki Ogawara points out that as the institute's scientists have to do everything themselves, it would be "almost beyond their capability" to man the operations desk 24 hours a day.

David Swinbanks

\section{Erato announces new research targets}

Tokyo

JAPAN's Research and Development Corporation has opted to support a mixed bag of projects this year under its unique Exploratory Research for Advanced Technology (ERATO) programme. ERATO, which has a history of heralding new lines of research that are being targeted by Japan.

The latest ERATO awards will support research on man-made $\pi$ electron materials, artificial molecular catalysts, biofouling and cell switching.

The ERATO programme, which won high praise in a study a few years ago by the US National Science Foundation (see $\mathrm{Na}$ ture 337,$196 ; 1989$ ), targets research with no immediate applications but that seems likely to produce applications in a few years. Each ERATO project provides a team of 15 to 20 young researchers (all under 35 except for the project leader) from industry and academic institutions with funds of \$2-\$3-million a year for five years - an enormous amount of money by Japanese government standards.

The fields chosen often give an indication of where Japanese research and development is heading. For example, ERATO has supported several projects in nanotechnology in the past few years, and industry and the Ministry of International Trade and Industry are now planning to launch a major national project in this area (see Nature 351, 90; 1991).

Four projects will begin this fiscal year. A team led by Susumu Yoshimura, director of Matsushita Research Institute in Tokyo, will try to find man-made materials which - like naturally occurring substances such as graphite and molecules involved in photosynthesis - carry piorbital electrons that can wander over large distances on the atomic or molecular scale and thus give unusual optical and/or electronic properties to materials.

Ryoji Noyori of Nagoya University's department of chemistry will lead a team that hopes to create new organometallic catalysts for such purposes as catalysing the formation of molecules or polymers that are specifically either left- or righthanded. Such materials, called optical isomers, often exhibit unusual optical, electrical or medical properties when produced with a pure handedness.

Other ERATO awards go to Hiroto Okayama of the Research Institute for Microbial Diseases in Osaka University, who will search for human genes which control the initial step of cell division and thus play a key role in cell growth and cancer development, and to a team led by Nebuhiro Fusekani at Tokyo University which will work on biofouling.

David Swinbanks 